\title{
Spatial environmental heterogeneity may drive functional trait variation in Hydrocotyle vulgaris (Araliaceae), an invasive aquatic plant
}

\author{
Ji-Zhong Wan ${ }^{1}$, Mo-Zhu Wang ${ }^{2}$, Tian-Jian Qin ${ }^{2}$, Xiang-Qi Bu ${ }^{2}$, Hong-Li Li ${ }^{2, *}$, \\ Fei-Hai $\mathrm{Yu}^{3,4}$ \\ ${ }^{1}$ State Key Laboratory of Plateau Ecology and Agriculture, Qinghai University, Xining 810016, PR China \\ ${ }^{2}$ School of Nature Conservation, Beijing Forestry University, Beijing 100083, PR China \\ ${ }^{3}$ Institute of Wetland Ecology \& Clone Ecology, Taizhou University, Taizhou 318000, PR China \\ ${ }^{4}$ Zhejiang Provincial Key Laboratory of Plant Evolutionary Ecology and Conservation, Taizhou University, Taizhou 318000, \\ PR China
}

\begin{abstract}
Invasive aquatic plants have the potential to threaten ecosystem stability and biodiversity in non-native ranges; it is therefore necessary to prevent and control such invasions. While environmental heterogeneity might drive functional trait variation in plant species across different spatial scales, the drivers of trait variation over a large spatial scale are not well understood for aquatic invasive plants. Understanding functional trait variation across space and potential environmental drivers might improve our understanding of habitable conditions for predicting where an invasive plant species might be found. Here, we studied Hydrocotyle vulgaris (Araliaceae) in Zhejiang Province, China, and propose that environmental spatial heterogeneity might drive functional trait variation of this invasive aquatic plant over a large scale. The investigation was conducted across 99 plots at 7 sites with $H$. vulgaris. We found significant variation in functional traits over a large scale, and these functional traits were significantly different across a variety of environmental conditions. Specifically, there were significant relationships between environmental factors (i.e. temperature, precipitation, solar radiation, and water vapor pressure) and functional traits, including specific leaf area, interval length, and specific interval length, indicating that spatial environmental heterogeneity might drive the variation in functional traits (especially leaf and clonal traits) of $H$. vulgaris, over a large spatial scale. Our study thus provides new insights into understanding the invasiveness of $H$. vulgaris.
\end{abstract}

KEY WORDS: China $\cdot$ Clonality $\cdot$ Environmental heterogeneity $\cdot$ Functional trait $\cdot$ Invasive aquatic plant

\section{INTRODUCTION}

Plant invasion has a negative impact on biodiversity and ecosystem function, resulting in large-scale social and economic effects (Willby 2007, Hershner \& Havens 2008, H. Wang et al. 2016). Rapid global change has the potential to enhance such impacts at a large scale (Vitousek et al. 1996, Bradley et al. 2010). Seebens et al. (2015) showed that global trade

${ }^{*}$ Corresponding author: lihongli327@163.com will accelerate invasions by alien plants in emerging economies under climate change. Invasive aquatic plants (IAPs) have been imported to non-native regions for ecological restoration, agricultural production, or even as ornamental plants around the world, and they have the ability to adapt to the environmental conditions of the new habitat and spread widely throughout non-native ranges (Thuiller et al. 2005, Hershner \& Havens 2008, Bradley et al. 2010,

(C) The authors 2019. Open Access under Creative Commons by Attribution Licence. Use, distribution and reproduction are unrestricted. Authors and original publication must be credited. 
Hussner 2012, P. Wang et al. 2016, C. Wang 2017). Furthermore, a period of repeated human colonization in relation to plasticity, establishment, and genetic adaptation to environmental changes can increase the probability of invasion by IAPs (Delaney et al. 2008, Wilson et al. 2009, Bradley et al. 2010). Once the invasion of IAPs occurs over a large spatial scale, there is a high risk that local plant diversity and ecosystem function might be lost (Theoharides \& Dukes 2007, Delaney et al. 2008, Hershner \& Havens 2008).

Stark et al. (2017) have shown that environmental heterogeneity can drive functional trait variation, and such variation might depend on the changes in plant traits. Environment-trait relationships are related to ecosystem function (e.g. productivity, decomposition, and soil carbon) and to ecosystem services (Lienin \& Kleyer 2012). Previous studies have shown that the invasiveness of alien plants might be related to the variation in functional traits under variable environmental conditions (Leishman et al. 2007, Pyšek \& Richardson 2008, Van Kleunen et al. 2010). Invasive plants have significantly higher plasticity, giving them an increased ability to adapt functional traits to new environments, such as physiology, leaf-area allocation, shoot allocation, growth rate, size, and fitness, compared to non-invasive species, and this might threaten the ecosystem function due to trait evolution and shifts in the environmental niche (Pyšek \& Richardson 2008, Tecco et al. 2010, Van Kleunen et al. 2010, C. Wang et al. 2017). The intermediate disturbance hypothesis indicates that alien invasion patterns could be shaped by increased environmental disturbance levels in human-modified habitats (e.g. through grazing and climate change; Saatkamp et al. 2010, Tecco et al. 2010, Catford et al. 2012).

Furthermore, experimental and field studies have identified differences in the traits of invasive plants, which might be due to spatial environmental heterogeneity (Tecco et al. 2010, Van Kleunen et al. 2010). Thus, ecologists and invasion biologists have predicted the trait variation of invasive plants under projected environmental changes, using functional traits as indicators of invasiveness, for the prevention and control of plant invasion (Moles et al. 2008, Van Kleunen et al. 2010). Therefore, the trait-environment relationship might provide appropriate references for the identification of the invasion mechanism and the conservation management of IAP species over large spatial scales (Willby 2007, Küster et al. 2008, Moles et al. 2008, Van Kleunen et al. 2010).

To investigate trait-environment relationships further, we studied the invasion of Hydrocotyle vulgaris (Araliaceae) over a large spatial scale. H. vul- garis is an aquatic herb native to Europe and North Africa that has invaded a wide range of habitats in Zhejiang Province, China (Miao et al. 2011, H. Wang et al. 2016). H. vulgaris is capable of expanding naturally in moist non-native areas, and its clonality contributes to its success as an invader (Miao et al. 2011, Liu et al. 2016). In addition, $H$. vulgaris can quickly establish itself in non-native areas (Miao et al. 2011, Liu et al. 2016). For example, $H$. vulgaris was introduced into Xixi Wetland in Zhejiang as an ornamental plant in the 1990s (Miao et al. 2011). It has since spread widely across this wetland, damaging the ecological landscape, and it is difficult to remove the plant due to its strong reproductive capacity (Miao et al. 2011). Hence, $H$. vulgaris is a useful representative species in Zhejiang Province to explore the relationship between spatial environmental heterogeneity and functional traits of IAPs over a large spatial scale. Furthermore, understanding of trait-environment relationships could help invasion biologists and government officials to recognize under which environmental conditions invasive species can survive and to manage the invasion, as well as to prevent and control further invasions of $H$. vulgaris both in Zhejiang Province and in other regions of China.

Here, we propose the hypothesis that environmental spatial heterogeneity might drive functional trait variation of the IAP $H$. vulgaris across a large scale. To test this hypothesis, 6 functional traits, including petiole length, interval length (a clonal trait), leaf area, specific interval length (a clonal trait), specific leaf area, and chlorophyll content, were used to test the trait-environment relationship for $H$. vulgaris across 99 study plots located at 7 field sites in Zhejiang Province and Shanghai City (the administrative region of Shanghai City was integrated into Zhejiang Province for this study; Axmacher \& Sang 2013, Liu et al. 2016, Stark et al. 2017, Wu et al. 2017). We explored the environmental drivers of functional trait variation in $H$. vulgaris to predict the functional traits across a large scale. Finally, we make some suggestions for the prevention and control of $H$. vulgaris invasion in Zhejiang Province.

\section{MATERIALS AND METHODS}

\subsection{Site selection}

We conducted a reconnaissance field investigation in July and August 2016 to identify locations with a 
continuous invasion of Hydrocotyle vulgaris in 7 cities in Zhejiang Province (including Shanghai, which does not belong to Zhejiang Province). Seven field sites were selected across these 7 cities (Hangzhou, Jiaxing, Lishui, Ningbo, Shanghai, Taizhou, and Wenzhou) along a latitudinal gradient in Zhejiang Province (Table 1, Fig. 1). We then randomly selected 10-26 field plots $\left(1 \times 1 \mathrm{~m}^{2}\right.$, at least $200 \mathrm{~m}$ apart $)$ at each site (Fang et al. 2009, Wu et al. 2017). In total, we established 99 plots within these 7 sites. We recorded the longitude and latitude above sea level for the field sites using a handheld GPS receiver (Garmin eTrex 20).

\subsection{Environment and functional trait measurements}

We used temperature, precipitation, solar radiation, and water vapor pressure as indicators of spatial environmental heterogeneity for the largescale analysis of functional trait variation (Fick \& Hijmans 2017). We compiled the annual mean and coefficient of variation (CV) data for temperature and precipitation based on the WorldClim version 2 database (Fick \& Hijmans 2017; www.worldclim. org/). In addition, we downloaded solar radiation and water vapor pressure data from January to December from the same WorldClim database, and computed the mean and standard deviation (SD) values of solar radiation and water vapor pressure annually (Fick \& Hijmans 2017). We used the SD as the $\mathrm{CVs}$ for solar radiation and water vapor pressure. These environmental variables are related to the distribution and physiological performance of invasive plants (Bradley et al. 2010). The resolution of environmental variables was 5.0 arc-minutes $\left(10 \times 10 \mathrm{~km}^{2}\right.$; Fick \& Hijmans 2017), and we found significant differences in environmental conditions across the 7 study sites (ANOVA; $\mathrm{p}<0.05)$.
We used petiole length ( $\left.\mathrm{PL}_{i} \mathrm{~cm}\right)$, interval length between interconnected ramets $\left(\mathrm{IL}_{i} \mathrm{~cm}\right)$, leaf area $\left(\mathrm{LA}_{i}\right.$ $\left.\mathrm{cm}^{2}\right)$, chlorophyll content $\left(\mathrm{CC}_{i} \mathrm{nmol} \mathrm{cm}{ }^{-2}\right)$, specific interval length ( $\mathrm{SIL}_{i} \mathrm{~cm} \mathrm{~g}^{-1}$ ), and specific leaf area (SLA; $\mathrm{cm}^{2} \mathrm{~g}^{-1}$ ) as relevant functional traits, as they are commonly thought to be linked to the major ecological strategies of plants, including clonal species (Klimešová et al. 2017; http://clopla.butbn.cas.cz/). We selected the dominant individual of $H$. vulgaris at each of the 99 plots to measure the 6 mentioned traits. PL and IL were measured in the field, and collected stems and leaves were stored in a cooler with ice packs and a damp paper towel. All plant parts were separately oven-dried at $70^{\circ} \mathrm{C}$ for at least $48 \mathrm{~h}$ and then weighed (Liu et al. 2016). LAs were scanned using an Epson Dual Lene system prior to drying. The SIL was calculated as the ratio of IL to dry leaf mass, and SLA was calculated as the ratio of LA to dry leaf mass (Liu et al. 2016). In addition, we used a SPAD502 chlorophyll content analyzer to evaluate $\mathrm{CC}$ in the field.

\subsection{Data analysis}

First, we used an ANOVA to detect significant differences in the plant functional traits between the environmental conditions (i.e. study sites) tested. Additionally, we ran a 1-way ANOVA with a Fisher LSD post hoc test for each environmental condition and study site to determine significant differences in the functional traits of $H$. vulgaris.

PCA was then used to determine the functional trait patterns of $H$. vulgaris based on the 6 measured functional traits: PL, IL, LA, SIL, SLA, and CC. We extracted the first principal components (PCs) accounting for more than $60 \%$ of the cumulative percentage variance of the functional traits. Thus, the PCs were used to determine the main functional trait patterns of $H$. vulgaris. The correlation matrix for the 6 traits produced by the PCA

Table 1. Mean \pm SD plant functional traits of Hydrocotyle vulgaris across 7 study sites in China

\begin{tabular}{|c|c|c|c|c|c|c|c|c|c|}
\hline Site & Code & $\begin{array}{l}\text { Longitude } \\
\qquad\left({ }^{\circ} \mathrm{N}\right)\end{array}$ & $\begin{array}{c}\text { Latitude } \\
\left({ }^{\circ} \mathrm{E}\right)\end{array}$ & $\begin{array}{l}\text { Petiole } \\
\text { length } \\
\text { (cm) }\end{array}$ & $\begin{array}{l}\text { Interval } \\
\text { length } \\
(\mathrm{cm})\end{array}$ & $\begin{array}{l}\text { Leaf } \\
\text { area } \\
\left(\mathrm{cm}^{2}\right)\end{array}$ & $\begin{array}{l}\text { Chlorophyll } \\
\text { content } \\
\left.(\mathrm{nmol} \mathrm{cm})^{-2}\right)\end{array}$ & $\begin{array}{c}\text { Specific interval } \\
\text { length } \\
\left(\mathrm{cm} \mathrm{g}^{-1}\right)\end{array}$ & $\begin{array}{c}\text { Specific leaf } \\
\text { area } \\
\left(\mathrm{cm}^{2} \mathrm{~g}^{-1}\right)\end{array}$ \\
\hline Ningbo & NB & 121.559 & 29.897 & $13.3 \pm 3.5$ & $6.4 \pm 2.0$ & $15.3 \pm 7.1$ & $31.6 \pm 2.1$ & $307.7 \pm 167.1$ & $469.5 \pm 70.3$ \\
\hline Jiaxing & JX & 120.774 & 30.699 & $18.7 \pm 9.8$ & $7.5 \pm 2.4$ & $21.5 \pm 15.4$ & $36.7 \pm 4.5$ & $161.3 \pm 72.4$ & $331.2 \pm 150.7$ \\
\hline Lishui & LS & 119.819 & 28.386 & $23.2 \pm 6.7$ & $6.8 \pm 2.7$ & $22.3 \pm 13.9$ & $34.2 \pm 3.3$ & $168.2 \pm 76.2$ & $316.9 \pm 130.8$ \\
\hline Wenzhou & WZ & 120.761 & 29.975 & $28.9 \pm 6.6$ & $6.3 \pm 5.6$ & $27.1 \pm 28.7$ & $39.7 \pm 31.8$ & $108.3 \pm 81.2$ & $309.5 \pm 233.6$ \\
\hline Taizhou & $\mathrm{TZ}$ & 121.427 & 28.673 & $16.4 \pm 6.0$ & $7.0 \pm 2.3$ & $20 \pm 11.7$ & $32.9 \pm 4.0$ & $253.4 \pm 106.6$ & $465 \pm 69.7$ \\
\hline Shanghai & $\mathrm{SH}$ & 121.442 & 31.149 & $17.6 \pm 6.3$ & $7.8 \pm 3.6$ & $24.1 \pm 8.8$ & $41.8 \pm 5.1$ & $161.1 \pm 117.1$ & $298.9 \pm 60.3$ \\
\hline Hangzhou & $\mathrm{HZ}$ & 120.39 & 30.313 & $15.5 \pm 4.8$ & $7.8 \pm 2.3$ & $14.2 \pm 6.0$ & $32.1 \pm 9.5$ & $247.6 \pm 110.7$ & $403.4 \pm 69.1$ \\
\hline
\end{tabular}




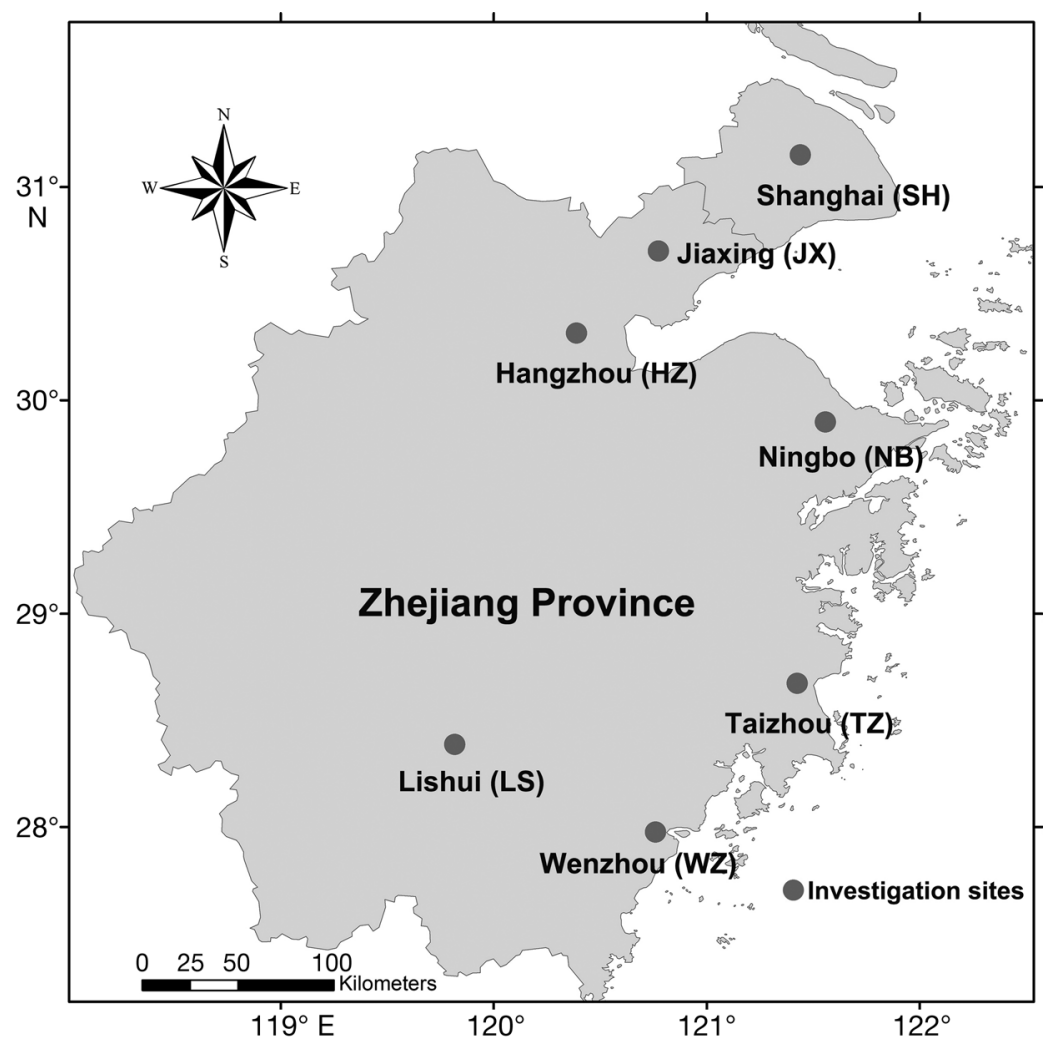

Fig. 1. Study sites in China, sampled to investigate differences in functional traits of Hydrocotyle vulgaris

was used to check the autocorrelation of the data. The autocorrelations were weak for the 6 traits (Table 2).

Finally, we used linear regression models to assess the relationship between the functional traits and environmental variables based on all 99 plots. The mean and SD of the functional traits were computed based on each investigation site to quantify functional trait variation (Stark et al. 2017). We performed linear and quadratic regression models for the relationship between mean traits, the SD of traits, and the environmental variables at the 7 main sites. The best-fitting models with the highest explained variances $\left(\mathrm{R}^{2}\right)$ for traitenvironment relationships were selected (Wu et al. 2017).

\section{RESULTS}

\subsection{Differences in plant functional traits}

We found significant differences among the different study sites (i.e. environmental conditions) for PL, LA, $\mathrm{CC}$, SIL, and SLA (ANOVA; $\mathrm{p}<0.05$; Table 3). Based on the Fisher LSD post hoc test, the largest differences were between Wenzhou and Ningbo for PL and SIL; Hangzhou and Wenzhou for IL; Hangzhou and Taizhou for LA; Shanghai and Taizhou for $\mathrm{CC}_{i}$ and Shanghai and Ningbo for SLA $(p<0.05$; Table S1 in the Supplement at www. int-res.com/articles/suppl/b028p149 _supp.pdf). SIL and SLA showed the greatest differences across a variety of environmental conditions and study sites $(\mathrm{p}<0.05$; Table S1). Hydrocotyle vulgaris had significantly greater PL in Wenzhou than in Ningbo, significantly greater IL in Hangzhou than in Wenzhou, significantly greater CC in Shanghai than in Taizhou, significantly smaller LA in Hangzhou than in Taizhou, significantly smaller SIL in Taizhou than in Ningbo, and significantly smaller SLA in Shanghai than in Ningbo (Table 1, and see Table S1).

\subsection{Patterns in functional traits}

There was a large variation in the means and SDs of the functional traits of $H$. vulgaris in Zhe-

Table 2. Correlation matrix for 6 plant functional traits of Hydrocotyle vulgaris across 99 investigation sites in China

\begin{tabular}{|lcccrrr|}
\hline & $\begin{array}{c}\text { Petiole } \\
\text { length }\end{array}$ & $\begin{array}{c}\text { Interval } \\
\text { length }\end{array}$ & $\begin{array}{c}\text { Leaf } \\
\text { area }\end{array}$ & $\begin{array}{c}\text { Chlorophyll } \\
\text { content }\end{array}$ & $\begin{array}{c}\text { Specific interval } \\
\text { length }\end{array}$ & $\begin{array}{c}\text { Specific leaf } \\
\text { area }\end{array}$ \\
\hline Petiole length & 1.000 & 0.221 & 0.636 & 0.129 & -0.447 & -0.045 \\
Interval length & 0.221 & 1.000 & 0.361 & 0.092 & -0.053 & -0.017 \\
Leaf area & 0.636 & 0.361 & 1.000 & 0.167 & -0.391 & 0.219 \\
Chlorophyll content & 0.129 & 0.092 & 0.167 & 1.000 & -0.125 & -0.355 \\
Specific interval length & -0.447 & -0.053 & -0.391 & -0.125 & 1.000 & 0.309 \\
Specific leaf area & -0.045 & -0.017 & 0.219 & -0.355 & 0.309 & 1.000 \\
\end{tabular}


Table 3. Differences in plant functional traits of Hydrocotyle vulgaris due to environmental conditions (i.e. associated with different study sites) using ANOVA

\begin{tabular}{|lcr|}
\hline Functional trait & $F$ & $\mathrm{p}$ \\
\hline Petiole length $(\mathrm{cm})$ & 10.382 & $<0.001$ \\
Interval length $(\mathrm{cm})$ & 1.026 & 0.414 \\
Leaf area $\left(\mathrm{cm}^{2}\right)$ & 3.256 & 0.006 \\
Chlorophyll content $\left(\mathrm{nmol} \mathrm{cm}{ }^{-2}\right)$ & 9.106 & $<0.001$ \\
Specific interval length $\left(\mathrm{cm} \mathrm{g}^{-1}\right)$ & 8.906 & $<0.001$ \\
Specific leaf area $\left(\mathrm{cm}^{2} \mathrm{~g} \mathrm{~g}^{-1}\right)$ & 5.393 & $<0.001$ \\
\hline
\end{tabular}

jiang Province (Table 1). The mean traits were the largest in the following locations: the PL $(18.7 \mathrm{~cm})$ in Jiaxing, IL $(7.8 \mathrm{~cm})$ in Shanghai and Hangzhou, LA $\left(27.1 \mathrm{~cm}^{2}\right)$ in Wenzhou, CC $\left(41.8 ; \mathrm{nmol} \mathrm{cm} \mathrm{cm}^{-2}\right)$ in Shanghai, and SIL $\left(307.7 \mathrm{~cm} \mathrm{~g}^{-1}\right)$ and SLA (469.5 $\mathrm{cm}^{2} \mathrm{~g}^{-1}$ ) in Ningbo (Table 1, Fig. 2). For the SD of traits, the PL $(9.8 \mathrm{~cm})$ in Jiaxing, IL $(5.6 \mathrm{~cm})$ and SLA $\left(233.6 \mathrm{~cm}^{2} \mathrm{~g}^{-1}\right)$ in Wenzhou, LA $\left(27.1 \mathrm{~cm}^{2}\right)$ and CC (31.8) in Wenzhou, and SIL (167.1 cm) in Ningbo were the largest of the 7 study sites (Table 1). The first 2 PCs explained a cumulative $60.1 \%$ of the variance in the functional traits. PC1 explained PL, LA, and SIL (36.5\%), and PC2 explained CC and SLA (23.6\%; Fig. 2). We found large functional trait differences between Ningbo and Wenzhou, Ningbo and Shanghai, Wenzhou and Hangzhou, and Shanghai and Hangzhou, while large overlaps of functional traits existed between Jiaxing and Lishui, Taizhou and Wenzhou, Jiaxing and Wenzhou, and Lishui and Wenzhou (Fig. 2).

\subsection{Environmental drivers of functional trait variation}

Significant relationships between functional traits and environmental variables existed for all 99 plots; however, the prediction powers of environmental variables for functional traits might depend on the type of functional trait and the environmental variables (Table S2). The CV of temperature had the strongest power to predict the variation in PL $\left(\mathrm{R}^{2}=\right.$ 0.234 ; accounting for $23.4 \%$; $<<0.01$ ). Spatial environmental heterogeneity accounted for more than $50 \%$ of the observed trait variation (Figs. $3 \& 4$ ). Regarding the mean functional traits, CC was best predicted by annual precipitation $\left(\mathrm{R}^{2}=0.932\right.$; $\mathrm{p}<$ 0.05 ; accounting for $93.2 \%$ of the observed trait variation; Fig. 3). Regarding the SD of functional traits, CC was best predicted by the CV of solar radiation $\left(\mathrm{R}^{2}=0.932 ; \mathrm{p}<0.01\right.$; accounting for $93.2 \%$ of the observed trait variation; Fig. 4). For clonal traits, the mean IL was predicted by the annual mean and the CV for temperature, the mean solar radiation, and the mean water vapor pressure $(\mathrm{p}<$ 0.05 ; accounting for more than $50 \%$ of the observed

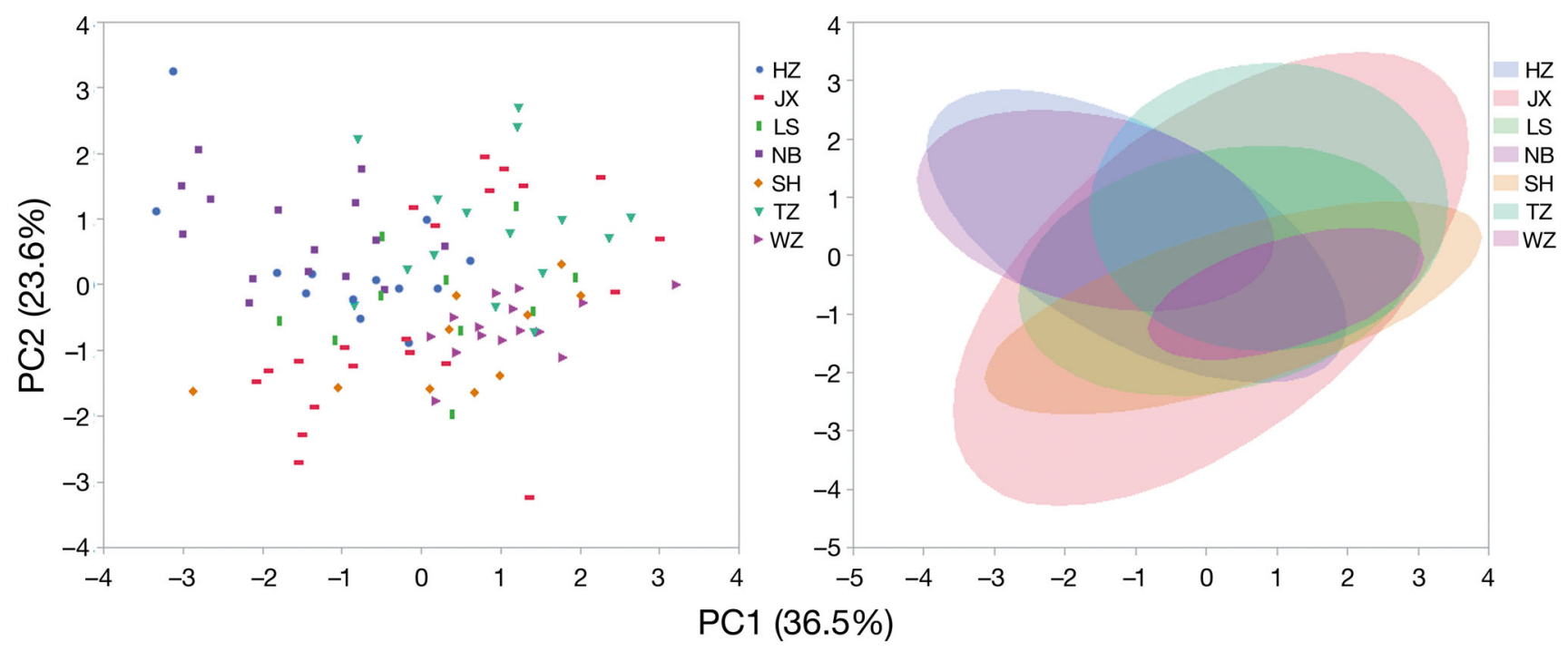

Fig. 2. PCA illustrating functional trait patterns of Hydrocotyle vulgaris. Codes of the study sites are the same as in Table 1 and Fig. 1. The scope of ranges was a $95 \%$ confidence level of functional traits based on the plots for each site. The overlap of ellipses indicates the similarity of functional traits among different investigation sites. PC1 explained petiole length, leaf area, and specific interval length (36.5\%), and PC2 explained chlorophyll content and specific leaf area (23.6\%) 

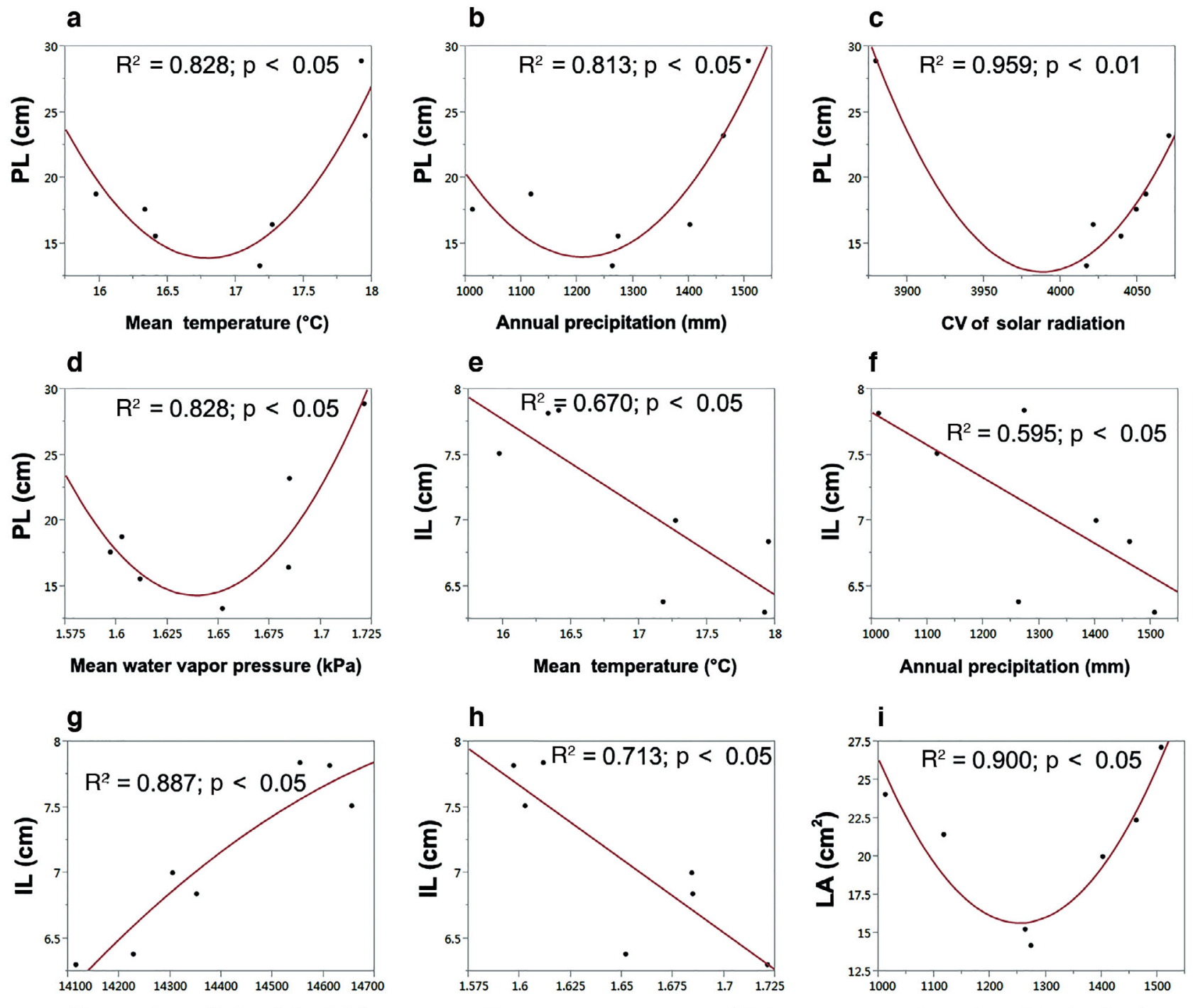

Mean solar radiation $\left(\mathrm{kJ} \mathrm{m}^{-2} \mathrm{~d}^{-1}\right)$

Mean water vapor pressure (kPa)

Annual precipitation $(\mathrm{mm})$
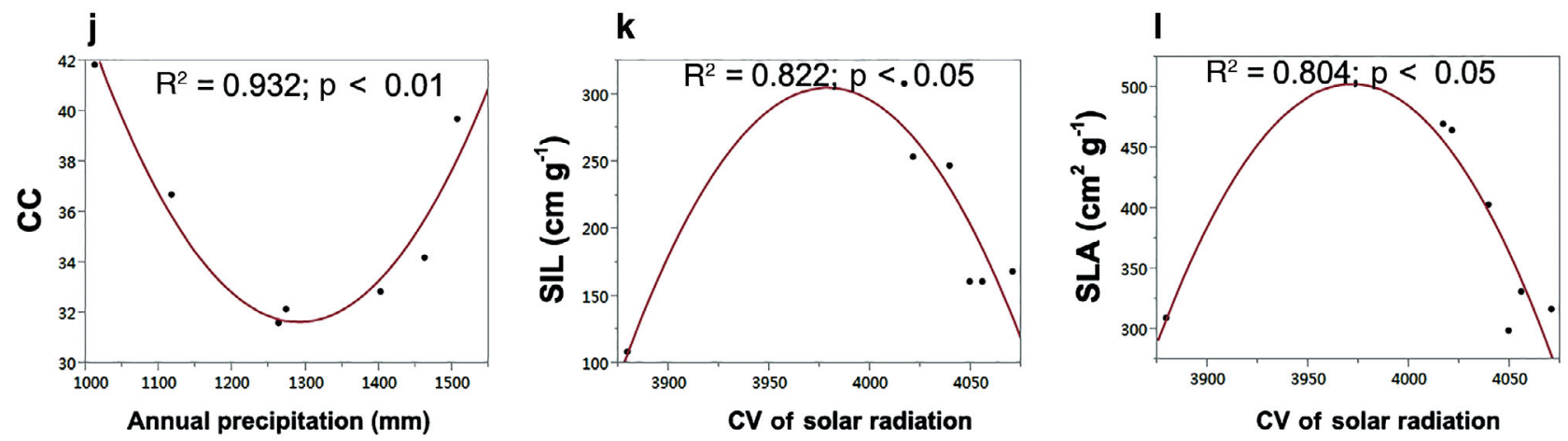

Fig. 3. Relationships between spatial environmental heterogeneity and mean functional traits of Hydrocotyle vulgaris. PL: petiole length; IL: interval length; LA: leaf area; SIL: specific interval length; SLA: specific leaf area; CC: chlorophyll content Only significant relationships are shown

trait variation), and mean SIL was derived from the mean solar radiation $(\mathrm{p}<0.05$; accounting for more than $50 \%$ of the observed trait variation; Fig. 3).
The SD of IL was predicted by the $\mathrm{CV}$ of solar radiation and the mean water vapor pressure $(p<0.05$; accounting for more than $85 \%$ of the observed trait 

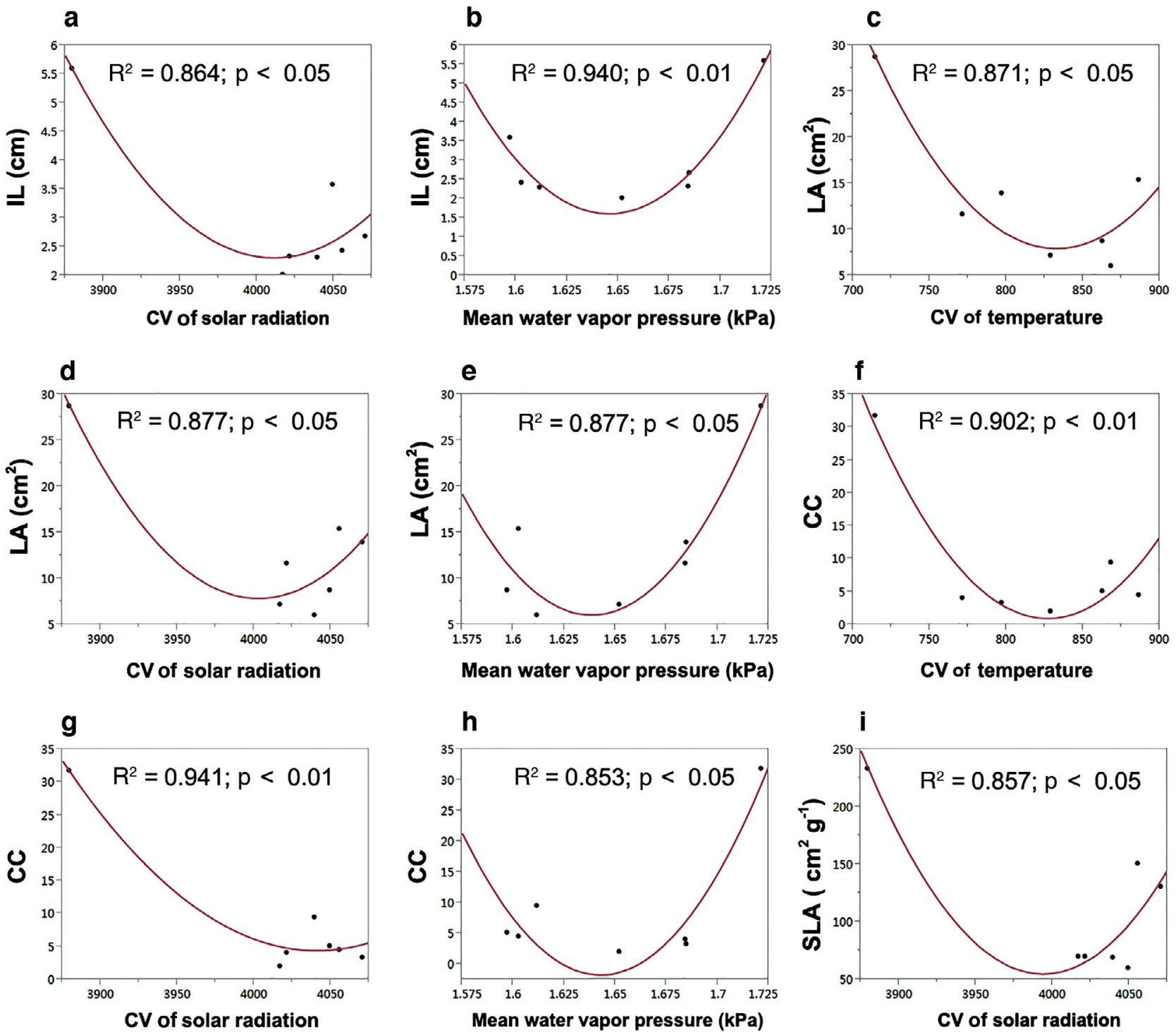

Fig. 4. Relationships between spatial environmental heterogeneity and the standard deviation of the functional traits of Hydrocotyle vulgaris. Abbreviations as in Fig. 3. Only significant relationships are shown

variation; Fig. 4). Both the mean and SD of the SLA were predicted by the $\mathrm{CV}$ of solar radiation $(\mathrm{p}<$ 0.05 ; accounting for more than $80 \%$ of the observed trait variation; Figs. $3 \& 4$ ). Furthermore, there were positive linear relationships between environmental factors (i.e. mean temperature, annual precipitation, mean solar radiation, and mean water vapor pressure), IL, and SIL (Fig. 3).

\section{DISCUSSION}

Our results indicated that spatial environmental heterogeneity (temperature, precipitation, solar radiation, and water vapor pressure) can drive functional trait variation of Hydrocotyle vulgaris in Zhejiang Province (Figs. $3 \& 4$ ), although the importance of each environmental factor varied depending on the trait of interest (Figs. $3 \& 4$ ). Hence, the hypothesis we proposed is partially supported by our findings. Other studies have also supported the relationship between trait variation and spatial environmental heterogeneity (Leishman et al. 2007, Pyšek \& Richardson 2008, Van Kleunen et al. 2010, Stark et al. 2017). For example, Stark et al. (2017) showed that environmental heterogeneity was the driver of functional trait variation based on a test in montane and alpine meadows. Our results provide further evidence of the relationship between environmental factors and functional traits in an IAP at the population level. 
Over our large study region, we identified vast differences in the functional traits of $H$. vulgaris, which may depend on the different environmental conditions at the study sites. SIL and SLA could contribute to the invasiveness of plant species (Van Kleunen et al. 2010); we found that SIL and SLA were the highest in Ningbo. SIL can be regarded as a clonal trait, and clonality has been positively related to the invasion ability of plant species by enhancing their ability to compete with native plants via clonal integration (Liu et al. 2006, P. Wang et al. 2016, Yu et al. 2016). Our results indicated that $H$. vulgaris had the greatest potential to invade Ningbo. Compared to Ningbo, Wenzhou and Shanghai might be less susceptible to invasion by $H$. vulgaris due to its smaller functional trait values in these areas (i.e. SIL and SLA). Our study provides clear evidence of regional differences in the functional traits of $H$. vulgaris, which can guide risk analyses for $H$. vulgaris invasion in Zhejiang Province.

Spatial environmental heterogeneity made a large contribution to the observed variation in functional traits of $H$. vulgaris (accounting for over $50 \%$ ). Less extreme environments, with respect to temperature, precipitation, solar radiation, and water vapor pressure, should support a broader range of plant strategies and thus higher trait variation (IL, LA, SIL, SLA, and $\mathrm{CC}_{i}$ Figs. 3 \& 4). Previous studies have shown that temperature and precipitation can be used to predict plant functional traits across a large scale (Stark et al. 2017, Wu et al. 2017). Furthermore, the heterogeneity of solar radiation and water vapor pressure can affect the trait evolution of invasive plants from experimental and field studies (Leeflang et al. 1998, Stark et al. 2017). Our study confirms that the mean and SD of leaf traits, such as LA and CC, can be predicted by temperature and precipitation. Annual precipitation and water vapor pressure are often interpreted as indicators of water availability, and temperature has a large contribution to the distribution and physiological performance of invasive plants from local communities to the global scale (Treurnicht et al. 2016, Stark et al. 2017, White et al. 2018). Water availability has a high potential to affect leaf traits along temperature gradients (Leishman et al. 2007, Messier et al. 2017), and the negative relationship between LA variation and mean temperature is consistent with energy balance strategies (Leishman et al. 2007, Stark et al. 2017). Solar radiation affects light acquisition in plant populations (Leeflang et al. 1998). Leeflang et al. (1998) showed that the petiole of $H$. vulgaris might respond to light gradients. In addition, we found a significant relationship between the SD of solar radiation and PL in our study. For example, SIL and SLA were the highest in Ningbo, and our results indicated that we could use solar radiation as an indicator of SIL and SLA of $H$. vulgaris in Ningbo. Hence, the spatial heterogeneity of temperature, precipitation, solar radiation, and water vapor pressure might be the driver of leaf trait variation in $H$. vulgaris, both among and within populations across a large scale. Species with leaf traits enabling rapid growth will be successful invaders when introduced to novel environments where resources are not limited (Leishman et al. 2007, Messier et al. 2017). Hence, we need to use environmental variation as an indicator of invasiveness based on the functional traits of IAPs. Of all 7 sites, we should pay attention to Ningbo due to the large values of SIL and SLA.

$H$. vulgaris can spread quickly by clonal growth in aquatic environments and is considered highly invasive in Zhejiang Province (Miao et al. 2011, Liu et al. 2016, H. Wang et al. 2016, Wan et al. 2019). Clonality increases plant invasion success worldwide (Yu et al. 2016). Clonal plants are able to successfully invade new habitats since they do not necessarily need to establish a population; they just need a single individual to do well enough to produce ramets (Kalusová et al. 2013, Dalrymple et al. 2015, Klimešová et al. 2017). We found that clonal traits, such as IL and SIL, were significantly related to changes in precipitation, solar radiation, and water vapor pressure, indicating that clonal traits of $H$. vulgaris could be predicted by spatial environmental heterogeneity over a large scale due to the phenotypic variation in these populations (Klimešová et al. 2017, Wan et al. 2019). These environmental variables (e.g. precipitation, solar radiation, and water vapor pressure) are possible drivers of plasticity in clones (Miao et al. 2011, Y. J. Wang et al. 2016, Wan et al. 2019). Experimental studies have shown that a heterogeneous water supply affects the clonal integration of $H$. vulgaris, including the growth and benefits of IL and SIL (You et al. 2013, P. Wang et al. 2016). Moreover, the positive linear relationships between environmental factors, IL, and SIL are related to plant invasiveness, indicating that regional environmental gradients could increase the invasive ability of $H$. vulgaris (You et al. 2013, Liu et al. 2016, Y. J. Wang et al. 2016). $H$. vulgaris could increase its competitiveness relative to native species, alter ecosystem function, and threaten native biodiversity in Zhejiang Province (Miao et al. 2011). Hence, our study provides the theoretical basis for the invasion of $H$. vulgaris and also describes how our results can be applied to the prevention and control of invasion by $H$. vulgaris. 
$H$. vulgaris is one of the most damaging IAPs in Zhejiang (particularly, Ningbo), and has damaged the ecosystems in the Xixi Wetland (Miao et al. 2011). It is a challenge for invasion biologists and government officials to manage the spread of $H$. vulgaris, which was introduced to China in the 1990s as an ornamental plant (Miao et al. 2011). To control and manage invasions by $H$. vulgaris, it is useful to predict its functional trait variation along environmental gradients (Van Kleunen et al. 2010, Stark et al. 2017); this could reduce the risk of invasion by $H$. vulgaris not only in Zhejiang Province, but also in other invaded regions around China.

\section{CONCLUSION}

Our study illustrates the importance of spatial environmental heterogeneity for functional traits, especially leaf and clonal traits, across a large spatial scale. This importance might depend on the different environmental conditions and investigation sites. We determined the environmental conditions and sites with a high risk of Hydrocotyle vulgaris invasion, such as Ningbo. Furthermore, we determined key traits with large variation such as SIL and SLA, along the changes of environmental conditions for $H$. vulgaris. This study provides effective guidance for prevention and control of this IAP on a large scale. However, since this study was limited by the amount of data available for ecological validation, a common-or-garden study is needed to understand whether spatial variation in functional traits is based on genetic differences or phenotypic plasticity. Although our study could account for the observed variance of functional traits in part, biotic and small-scale abiotic factors are also drivers of functional trait variation of IAPs. Hence, further studies are needed to analyze the relationship between spatial environmental heterogeneity and functional trait variation of IAPs over smaller spatial scales.

Acknowledgements. We thank the Editor and 2 reviewers for their useful comments, which helped improve our manuscript, and Shao-Ke Li for help with plant collections. Research was supported by the National Key Research and Development Program (2016YFC1201100), the Fundamental Research Funds for the Central Universities (2015ZCQBH-01), the National Natural Science Foundation of China (31800449), the Technology Program for Water Pollution Control and Treatment (2017ZX07602-004-003), and the Basic Research Project of Qinghai Province, China (2019ZJ-936Q).

\section{LITERATURE CITED}

Axmacher JC, Sang W (2013) Plant invasions in China-challenges and chances. PLOS ONE 8:e64173

Bradley BA, Blumenthal DM, Wilcove DS, Ziska LH (2010) Predicting plant invasions in an era of global change. Trends Ecol Evol 25:310-318

Catford JA, Daehler CC, Murphy HT, Sheppard AW and others (2012) The intermediate disturbance hypothesis and plant invasions: implications for species richness and management. Perspect Plant Ecol Evol Syst 14:231-241

* Dalrymple RL, Buswell JM, Moles AT (2015) Asexual plants change just as often and just as fast as do sexual plants when introduced to a new range. Oikos 124:196-205

* Delaney DG, Sperling CD, Adams CS, Leung B (2008) Marine invasive species: validation of citizen science and implications for national monitoring networks. Biol Invas 10:117-128

Fang J, Wang X, Shen Z, Tang Z and others (2009) Methods and protocols for plant community inventory. Biodivers Sci 17:533-548

* Fick SE, Hijmans RJ (2017) WorldClim 2: new 1-km spatial resolution climate surfaces for global land areas. Int $\mathrm{J}$ Climatol 37:4302-4315

* Hershner C, Havens KJ (2008) Managing invasive aquatic plants in a changing system: strategic consideration of ecosystem services. Conserv Biol 22:544-550

Hussner A (2012) Alien aquatic plant species in European countries. Weed Res 52:297-306

*Kalusová V, Chytrý M, Kartesz JT, Nishino M, Pyšek P (2013) Where do they come from and where do they go? European natural habitats as donors of invasive alien plants globally. Divers Distrib 19:199-214

Klimešová J, Danihelka J, Chrtek J, de Bello F, Herben T (2017) CLO-PLA: a database of clonal and bud bank traits of Central European flora. Ecology 98:1179

K Küster EC, Kühn I, Bruelheide H, Klotz S (2008) Trait interactions help explain plant invasion success in the German flora. J Ecol 96:860-868

* Leeflang L, During HJ, Werger MJA (1998) The role of petioles in light acquisition by Hydrocotyle vulgaris L. in a vertical light gradient. Oecologia 117:235-238

Leishman MR, Haslehurst T, Ares A, Baruch Z (2007) Leaf trait relationships of native and invasive plants: communityand global-scale comparisons. New Phytol 176:635-643

Lienin P, Kleyer M (2012) Plant trait responses to the environment and effects on ecosystem properties. Basic Appl Ecol 13:301-311

Liu J, Dong M, Miao SL, Li ZY, Song MH, Wang RQ (2006) Invasive alien plants in China: role of clonality and geographical origin. Biol Invas 8:1461-1470

Liu L, Quan H, Dong BC, Bu XQ and others (2016) Nutrient enrichment alters impacts of Hydrocotyle vulgaris invasion on native plant communities. Sci Rep 6:39468

Messier J, McGill BJ, Enquist BJ, Lechowicz MJ (2017) Trait variation and integration across scales: Is the leaf economic spectrum present at local scales? Ecography 40: 685-697

Miao L, Ji M, Wang Y, Qiao D, Chen Y (2011) Study on invasion risk of Hydrocotyle vulgaris as an alien species in wetlands. J Zhejiang Univ 37:425-431

Moles AT, Gruber MA, Bonser SP (2008) A new framework for predicting invasive plant species. J Ecol 96:13-17

Pyšek P, Richardson DM (2008) Traits associated with invasiveness in alien plants: Where do we stand? In: Nentwig 
W (ed) Biological invasions. Ecological Studies (Analysis and Synthesis), Vol 193. Springer, Berlin, p 97-125

Saatkamp A, Römermann C, Dutoit T (2010) Plant functional traits show non-linear response to grazing. Folia Geobot 45:239-252

Seebens H, Essl F, Dawson W, Fuentes N and others (2015) Global trade will accelerate plant invasions in emerging economies under climate change. Glob Change Biol 21: 4128-4140

Stark J, Lehman R, Crawford L, Enquist BJ, Blonder B (2017) Does environmental heterogeneity drive functional trait variation? A test in montane and alpine meadows. Oikos 126:1650-1659

Tecco PA, Díaz S, Cabido M, Urcelay C (2010) Functional traits of alien plants across contrasting climatic and landuse regimes: Do aliens join the locals or try harder than them? J Ecol 98:17-27

Theoharides KA, Dukes JS (2007) Plant invasion across space and time: factors affecting nonindigenous species success during four stages of invasion. New Phytol 176: 256-273

Thuiller W, Richardson DM, Pyšek P, Midgley GF, Hughes GO, Rouget M (2005) Niche-based modelling as a tool for predicting the risk of alien plant invasions at a global scale. Glob Change Biol 11:2234-2250

Treurnicht M, Pagel J, Esler KJ, Schutte-Vlok A and others (2016) Environmental drivers of demographic variation across the global geographical range of 26 plant species. J Ecol 104:331-342

Van Kleunen M, Weber E, Fischer M (2010) A meta-analysis of trait differences between invasive and non-invasive plant species. Ecol Lett 13:235-245

Vitousek PM, Antonio CM, Loope LL, Westbrooks R (1996) Biological invasions as global environmental change. Am Sci 84:468

Wan JZ, Wang CJ, Yu FH (2019) Large-scale environmental

Editorial responsibility: Brant Touchette,

Elon, North Carolina, USA niche variation between clonal and non-clonal plant species: roles of clonal growth organs and ecoregions. Sci Total Environ 652:1071-1076

*Wang CJ, Wan JZ, Qu H, Zhang ZX (2017) Climatic niche shift of aquatic plant invaders between native and invasive ranges: a test using 10 species across different biomes on a global scale. Knowl Manag Aquat Ecosyst 418:27

*Wang H, Wang Q, Bowler PA, Xiong W (2016) Invasive aquatic plants in China. Aquat Invas 11:1-9

Wang P, Alpert P, Yu FH (2016) Clonal integration increases relative competitive ability in an invasive aquatic plant. Am J Bot 103:2079-2086

*Wang YJ, Bai YF, Zeng SQ, Yao B, Wang W, Luo FL (2016) Heterogeneous water supply affects growth and benefits of clonal integration between co-existing invasive and native Hydrocotyle species. Sci Rep 6:29420

*White HJ, Montgomery WI, Pakeman RJ, Lennon JJ (2018) Spatiotemporal scaling of plant species richness and functional diversity in a temperate semi-natural grassland. Ecography 41:845-856

*Willby NJ (2007) Managing invasive aquatic plants: problems and prospects. Aquat Conserv 17:659-665

*Wilson JR, Dormontt EE, Prentis PJ, Lowe AJ, Richardson DM (2009) Something in the way you move: dispersal pathways affect invasion success. Trends Ecol Evol 24:136-144

Wu H, Carrillo J, Ding J (2017) Species diversity and environmental determinants of aquatic and terrestrial communities invaded by Alternanthera philoxeroides. Sci Total Environ 581-582:666-675

*You W, Yu D, Liu C, Xie D, Xiong W (2013) Clonal integration facilitates invasiveness of the alien aquatic plant Myriophyllum aquaticum L. under heterogeneous water availability. Hydrobiologia 718:27-39

Yu FH, Roiloa SR, Alpert P (2016) Global change, clonal growth, and biological invasions by plants. Front Plant Sci 7:1467

Submitted: December 10, 2018; Accepted: August 1, 2019

Proofs received from author(s): October 18, 2019 